\title{
Gambling addiction
}

This man struggled with a gambling addiction for some years before eventually seeking help. He describes how his condition seriously affected his relationship with his partner and talks about the treatment that finally helped him to stop gambling

\section{patient ${ }^{1}$, Henrietta Bowden-Jones consultant psychiatrist ${ }^{2}$ lead clinician ${ }^{3}$ honorary senior lecturer ${ }^{4}$, Sanju George consultant, senior research fellow, and honorary senior lecturer in addiction psychiatry ${ }^{5}$}

${ }^{1} \mathrm{UK} ;{ }^{2}$ Addictions Directorate, Central North West London NHS Foundation Trust, London NW1 2PL, UK ; ${ }^{3}$ National Problem Gambling Clinic, London W1D $3 \mathrm{HZ} ;{ }^{4}$ Department of Medicine, Imperial College London, London SW7 2AZ ; ${ }^{5}$ Birmingham and Solihull Mental Health NHS Foundation Trust, Birmingham B37 7UR, UK

I graduated from King's College, London with a BSc in human biology so I'm not a stupid man, and I'm aware of some of the psychobiological science behind addiction. Despite this, I am evidently capable of stupid acts; illogical, irrational, and emotional acts that undermined my future, my relationship, my family.

I'm 32. I am a financial services head hunter-a well paid job if it goes well but risky too as deals that would generate big fees often fail at the last minute beyond my control. I have a love-hate relationship with this type of stress as it's 24 hour but also exciting and full of possibilities. The clients and candidates I mix with often run global franchises and earn millions, and this rarefied environment became the norm I aspired to. I undervalued what I had in my life (for example, health, family, relationships, job) and overvalued what I perceived I didn't have (success, money, material things).

My earliest memory of gambling is playing the children's card game "top trumps" at primary school, in which the winner takes all. As a child I spent a lot of time at a working man's club where my alcoholic father took my brother and me. In a large smoky room, we'd play 20p stake dominoes with Frank, "Doughnut" (the baker), and their old cronies. They were happy to have us in the game. Sometimes we'd win and they'd complain that kids shouldn't be gambling. It was all light-hearted and is a fond memory. Later, my brother and I started to play on the fruit machines. My brother had a system relating to the sound the coins made in the tubes that signalled a "payout window," and a specific route of pubs he'd visit with the same type of machine. As an adult and as part of my job I would sometimes go to casinos with colleagues and clients. I enjoyed those times. Casinos have an attractive air of wealth and success. A mix of decadent relaxation and stress relief, they are also exciting and full of possibilities. I started gambling more and more.

My gambling cycle was as follows:

Lose, chase a loss, lose again-then I'd feel awful, angry, disappointed; I'd lie and deceive to cover up the loss, which led to damaged self esteem and ego, depression, hopelessness, chronic anxiety, lack of focus on anything other than the issues around gambling losses, fear, loss of enjoyment in other things and so on.

Win some-but never as much as the total loss, so although I may have felt a very swift uplift in mood, it didn't really feel good as I knew there was still a debt to service. What's more, those wins would be either pocketed and returned another day or simply bet again there and then and lost.

Return to the casino-to repeat the same cycle of warped logic that I could "win" back the losses.

Gambling quickly became no longer a bit of fun but a means to an end-the only way to get back to zero. I didn't feel special anymore. I wanted only sanitary transactions-sit, bet, win, leave. There was no interaction with the croupier, no stories with fellow gamblers, just the job of winning it back. My bets would start small and increase without a discernible strategy. Most of the time I felt numb, emotionless, and robotic. At other times I felt depressed and "doomed to lose" but irrationally felt that it was the only way out of this mess and so continued on to the inevitable outcome.

I risked as much as I could. I lied to myself and my partner and spent our money as though it was my own. I unilaterally made decisions that materially affected our lives and led my partner to make painful decisions, like cancelling our wedding. I knew what she didn't know: that I'd spent our money and owed large sums on credit cards. I could think of nothing else. I woke up 
and the first thing I'd think about was the debts and the lies. Daily conversations inevitably revolve around money, either directly or through its requirement to do things: visiting family, shopping for food, drinking with friends, travelling to work, and so on. I desperately tried to avoid conversations with any connection to money. I longed for each day to end so I could go to sleep and just get through it.

I became utterly deceitful. I changed our joint account to online banking so nothing was sent to our home address. I made my partner feel bad about opening anything addressed to me in case she accidentally found one of the statements that was sent to me at home. When we went shopping I'd send her off to get something so I could pay for the shopping on a credit card while she was away as I knew my bank card would be rejected.

Within a few years I ended up with $£ 28000$ of debts. That doesn't include interest paid on credit card balances, overdraft fees and breach charges, $0 \%$ credit card transfer fees, and so on. So the number is probably closer to double that. I reached the point where I couldn't afford to gamble anymore. I was forced to disclose the depth of the situation and my lies to my partner.

Once I'd told her of the debts, I felt a sense of relief. Needless to say there was a whole panoply of emotions. Good days. Bad days. Sometimes tears, sometimes shouting, sometimes nothing-and everything in between. She didn't leave me. She came very close to doing so and still questions if she should for fear of becoming an enabler of a problem, but we're together for now.

I wanted to do everything I could to rectify the situation for the benefit of my relationship and myself. I went online and found Gamblers Anonymous. It was encouraging to read comments on forums describing similar experiences and familiar thoughts and feelings. I booked a date to attend one of their meetings. Sadly, that wasn't a wholly positive experience for me. I met a large number of people (60 or so), but it felt a bit

religious/cultish. There was definitely unspoken peer pressure to conform to their way, which is a little too attractive to people addicted to that kind of rehabilitation environment, I believe. However, I met a couple of people who left a real impression on me, and I learnt a couple of key points that stick in my mind as proving useful in my own journey. One of those is, "I cannot win if I cannot stop," a thoroughly rational, objective view, of which I'm always mindful. The other was the Gamblers Anonymous motto, which is essentially "Change the things you can, ignore the things you can't, and understand the difference." This has implications in life generally aside from just gambling rehabilitation, and it strikes a chord in me. It makes me feel powerful and potent enough to make significant changes for the better but rational enough to focus only on those things I can change.

Still searching the internet for ways to understand and approach a gambling problem, I found a self referral link to the eight session cognitive behavioural therapy (CBT) group at the gambling clinic in London. As I have a basic understanding of CBT and neurolinguistic programming this appealed to me and I approached the clinic. Following an interview I was accepted on to the course, learnt strategies, and built a toolkit to understand stimuli, impulse control, defining positive alternatives to gambling, and so on.

This pragmatic and forward looking "what now?" approach has proved to be wholly complementary to the retrospective "why?" approach that psychotherapy has offered so far. Now I've gone 10 weeks without gambling and, for me, the clinic defines the "change the things you can" part of the motto. This clearly illustrates that things can be changed by the individual, but the clinic also offers practical advice on what the key things to change may be and what techniques can be used to break old patterns and create new, positive ones. The rest, the hard work, as always, is up to me.

Competing interests: HB-J and SG have completed ICMJE uniform disclosure form at www.icmje.org/coi_disclosure.pdf (available on request from the corresponding author) and declare: no support from any organisation for the submitted work; no financial relationships with any organisations that might have an interest in the submitted work; no other relationships or activities that could appear to have influenced the submitted work.

Provenance and peer review: Not commissioned; not externally peer reviewed.

Accepted: 28 October 2011

Cite this as: BMJ 2011;343:d7789

(c) BMJ Publishing Group Ltd 2011 


\section{A doctor's perspective}

\section{Gambling}

Gambling can be described as putting something, usually money, at risk, in the hope of gaining something of greater value. It is a pastime engaged in by $73 \%$ of British adults.

For a small minority $(0.9 \%)$ it can develop into a problem, known as problem gambling (box 1). Gambling behaviours, like alcohol use, exist on a scale of escalating severity and adverse consequences, ranging from social and recreational gambling, through "at risk" gambling and problem gambling, to gambling addiction. Gambling addiction can negatively affect the individual (physical problems such as stress related symptoms or conditions, and psychiatric problems such as depression, anxiety spectrum disorders, and substance misuse), their family (for example, relationship problems, domestic violence, neglect of children), and wider society (crime, absenteeism from work, and so on).

\section{Detecting the problem}

Problem gamblers are very reluctant to seek help because of a fear of stigma or because of guilt and shame about the gambling behaviour and its consequences.

In requesting help, they present more often to non-specialists than specialists and they do so with "non-direct" presentations such as physical symptoms, psychiatric complaints, financial difficulties, legal problems or domestic violence. This, coupled with healthcare professionals' lack of awareness and knowledge of the disorder, often leads to gamblers going undetected, and their problems remaining unaddressed. It has been described as the "hidden addiction" for these reasons. We suggest a consistent screening of these "high risk" patient groups: those presenting with non-specific physical complaints and stress related symptoms; those with psychiatric conditions such as depression, anxiety, and alcohol misuse; those who commit domestic violence; and those with financial difficulties.

Various questionnaires are available to screen for gambling but we suggest the Lie/Bet screening tool because of its brevity. The Lie/Bet screen is a two question screening instrument; the questions are "Have you ever felt the need to bet more and more money?" and "Have you ever had to lie to people important to you about how much you gamble?" A positive response to either question identifies a person who is likely to be a problem gambler.

\section{Interventions}

Very effective, evidence based brief interventions for problem gambling, similar to those used in alcohol misuse, can easily be delivered in 5 to 10 minutes by non-specialists. Where resources or expertise do not permit this, refer patients to specialist gambling treatment services (box 2); patients can also self refer to these agencies.

Psychological treatments (one to one or in groups) are the cornerstone of treating gambling problems, with cognitive behavioural therapy being the most commonly and effectively used. Gamblers Anonymous, a self help group modelled on Alcoholics Anonymous, is another widely available source of psychological treatment. Pharmacotherapy still has only a small role in the treatment of this condition: although selective serotonin reuptake inhibitors, mood stabilisers, and naltrexone have all been tried with some success, no drug is licensed yet for the treatment of pathological gamblers in the UK.

However, the National Problem Gambling Clinic will begin prescribing naltrexone from 2012 as part of its evidence based practice.

The Responsible Gambling Fund (www.rgfund.org.uk), the major commissioning body for gambling research, education, harm prevention, and treatment in Britain has recently funded the Royal College of General Practitioners to train general practitioners to support patients with gambling problems; for further information contact the royal college (rcgp.org.uk). The Responsible Gambling Fund also funds both the National Problem Gambling Clinic, the first NHS multidisciplinary treatment service specifically set up to treat pathological gamblers, and Gamcare, the charity that delivers counselling to problem gamblers across the UK.

Henrietta Bowden-Jones, consultant psychiatrist.

\section{Box 1 Patterns of excessive gambling}

\section{"At risk" gambling}

Excessive gambling that carries the increased risk of developing into a gambling problem in the future but has not yet resulted in major adverse effects.

\section{Problem gambling}

Gambling that disrupts or damages personal, family, or recreational pursuits.

\section{Gambling addiction or pathological gambling}

Persistent and recurrent maladaptive gambling behaviour, characterised by some of the following: preoccupation with gambling, need to gamble with increasing amounts, inability to cut back or stop, "chasing" losses, lying about gambling, adverse social and financial consequences.

\section{Box 2 Useful resources}

National Problem Gambling Clinic (www.cnwl.nhs.uk/gambling.html)—Designated NHS service to help people with gambling problems Royal College of Psychiatrists' information leaflet on problem gambling (www.rcpsych.ac.uk/mentalhealthinfoforall/problems/ problemgambling.aspx)

Gamblers Anonymous (www.gamblersanonymous.org.uk)—A self help group modelled on Alcoholics Anonymous

GamCare (www.gamcare.org.uk)—A non-governmental organisation providing support, information, and advice to anyone with a gambling problem 